Portland State University

PDXScholar

Engineering and Technology Management

Faculty Publications and Presentations

2019

\title{
The Main Sources for Technology Management Research: A Bibliometric Approach
}

Tugrul Daim

Portland State University, tugrul@etm.pdx.edu

H Yalcin

Izmir Katip Celebi University

Follow this and additional works at: https://pdxscholar.library.pdx.edu/etm_fac

Part of the Business Administration, Management, and Operations Commons

Let us know how access to this document benefits you.

Citation Details

(c) Copyright 2020 IEEE

This Article is brought to you for free and open access. It has been accepted for inclusion in Engineering and Technology Management Faculty Publications and Presentations by an authorized administrator of PDXScholar. Please contact us if we can make this document more accessible: pdxscholar@pdx.edu. 


\title{
The Main Sources for Technology Management Research: A Bibliometric Approach
}

\author{
Tugrul Daim ${ }^{1}$, Haydar Yalcin ${ }^{2}$ \\ ${ }^{1}$ Department of Engineering and Technology Management Portland State University, Portland, USA \\ ${ }^{2}$ Department of Information Management, Izmir Katip Celebi University, Izmir, Turkey
}

\begin{abstract}
In this study, it is aimed to determine the main sources of Technology Management (TM) field. Since there are many bibliographic databases, it is important to identify which journal is the most important in T.M., and there are many journals published in this field, it is possible to decide which one is the most important journal for TM. For this purpose, a series of analyzes were performed on bibliographic data of the publications indexed in Web of Science using bibliometrics. The main purpose of the study is to identify and rank the most important journals in the field of TM. In this way, it will be possible to determine the most important publications in the field of TM. To determine the main journal list for the TM area, Bradford law will be used, and citation analysis methods will be used to determine the impact of journals in the field.
\end{abstract}

\section{INTRODUCTION}

Technology management (TM) can be defined as a multidisciplinary field that integrates personnel and project management skills with the solid knowledge of technological systems and operations[1-3]. It is a process that must be managed to provide a competitive advantage for the organizations by effectively integrating and developing the technologies needed by the organizations [4-6]. TM is critical to make the investments of companies or corporations in technology correctly and accurately. In this respect, it is necessary to know the basic features of TM. It is possible to mention two basic social structures, namely the handling of technology management by field working professionals and their handling in terms of academic research. It is possible to say that qualified academic knowledge is produced and then applied in the field in professional work life. In this context, it is very important to determine the points where the academic structure seeks to resolve the TM. To determine the basic dynamics within the academic structure, it is necessary to identify the publications in the field of technology management and to identify the publications cited in these publications. The area of technology management has gained importance during the last decades. Accordingly, the number of studies, publications, and journals in this area has increased. It is important to define the main actors in the technology management area in many aspects such as identification of authors, identification of research gaps, research collaboration and so on. Defining the research focal points, defining the roles of researchers based on individuals and institutions and identifying the roles they undertake will make them easier to identify. For this reason, it is possible to define research question in our research:
RQ. Which journals are the most important in the Technology Management area? In terms of number of papers, citation metrics and h-index measures.

\section{REVIEW}

In the literature, it is possible to find many studies conducted in various sectors for technology management [720]. In some of these studies, it is observed that the methods used in technology management are tested and the policies conducted in country or region are evaluated. When we examine the literature, it is possible to see that technology management is handled with social change. For example, Whip highlighted the opportunities and the threats that arise in order to control the technological change in his study [5]. He made a sampling from the automobile sector in his work that proposes to think technology together with the environment. Another study examining the coordination of information technologies with company strategies Baets, (1992) integrates the existing theoretical concepts in information management with them and the process of defining the corporate strategy definition process with the information technology strategy definition process [6]. On the other hand, the technology management literature, which is also used in the creation of technology road maps, has been used together with bibliometric methods in order to obtain results in the context of technology foresight [21]. The bibliometrics is also used to reveal the general characteristics of scientific journals [22-24].

\section{Methodology}

Since there are many bibliographic databases, it is important to identify which journal is the most important in T.M., and there are many journals published in this field, it is possible to decide which one is the most important journal for TM. An online query was used at WoS, for this purpose ${ }^{1}$. Main purpose of this research is to determine the core journals for TM.

We used several methods to reveal this information such as citation analysis, productivity analysis and main path analysis. In this context, the most frequently published journals in the field of technology management have been identified. In this research, the main features of the technology management

\footnotetext{
${ }^{1} \mathrm{ALL}=($ "Technology Management") OR ALL=("Management of Technology") OR ALL=("Engineering Management") Timespan: 19002018. Indexes: SCI-EXPANDED, SSCI, A\&HCI, CPCI-S, CPCI-SSH, BKCI-S, BKCI-SSH, ESCI, CCR-EXPANDED, IC
} 
literature were examined using bibliometrics and the scientometrics. Bibliometrics can be use for the basic dynamics for any discipline $[23,25]$. On the other hand, it is observed that this method is used for profiling journals which are the leading scholarly communication tools [22-24]. This method is also used to measure and visualize scientific communication [26]. In this context, the most frequently published journals in the field of TM have been identified. On the other hand, the sources cited frequently in the area were identified. Since the abbreviated title of the cited journals have been reached, SHERPA / RoMEO API was used to access the full titles of the journals and ISSNs. The query was sent for the abbreviation title of each journal and the results were stored in a relational database.

\section{1) Citation Analysis}

a) Cited Journals Analysis

It is possible to determine the relevant important sources in the field through the cited publications. For this purpose, frequently cited sources have been determined through the citation data of journals frequently published in the field of technology management. The sources (journals, books etc.) cited frequently in the area were identified. There are 30506 individual cited journals. According to the results of citation analysis, a total of 361580 times cited in 30536 single journals in TM studies. $70 \%$ of the 361580 citations are made to the first 618 journals. In other words, the first 618 of the frequently cited journals meet $70 \%$ of the citations.

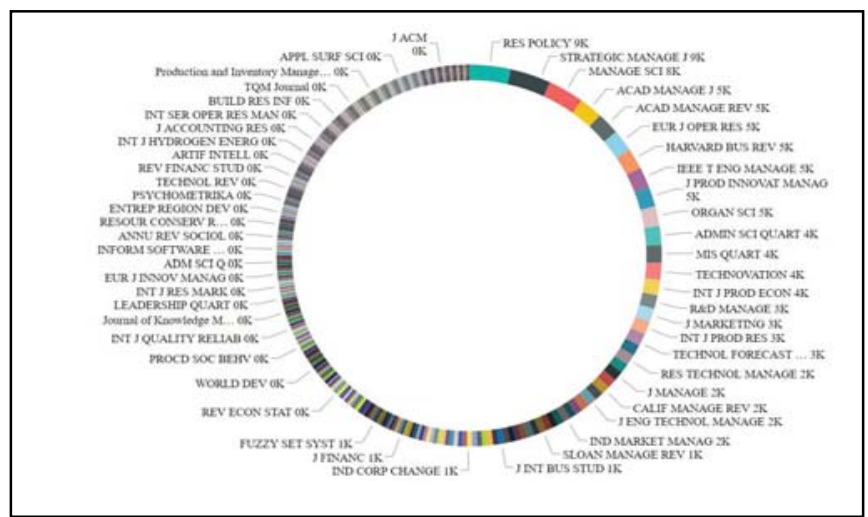

Fig. 1. Most Cited Journals in TM research

Since the abbreviated title of the cited journals have been reached, SHERPA / RoMEO API2 was used to access the full titles of the journals and ISSNs. The query was sent for the abbreviation title of each journal and the results were stored in a relational database. Then the journals are compiled with the information in the journal citation reports database and the impact factors and the other details of the journals are compiled. The aim of this course is to comprehend the concepts of the documents published in the field of TM. In this context, the text mining method has been utilized to examine the essence of the documents. For this purpose, using the Lingua :: Sentence3 module developed in Perl, the concepts contained in document abstracts can be grouped together. In the coding of the concepts, the Penn Treebank protocol was used to identify the concepts.

\section{RESUlts}

There are 33130 documents and 37943 units counted. While the number of publications with single authors was 12572, 29 authors contributed to the article with the highest number of authors. When we examine the number of authors per article, it is possible to say that there is an increase in the number of articles with multiple authors. In other words, it is worth noting that there is an increasing tendency of collaboration (collaboration index $=1.54$ ). When we examine the number of publications per year, it is possible to say that the publications in the TM area continue to increase every year4 (Figure 1). The annual growth rate for TM is calculated as $\% 9.983375$.

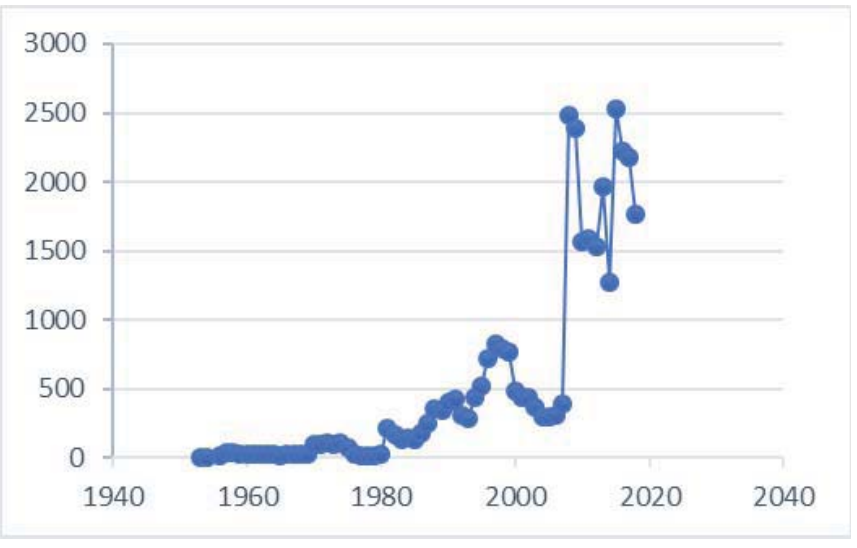

Fig. 2. Annual Growth Rate

2) Core Sources Analysis and Bradford's Law Of Scattering

To determine the publications used frequently in the field of TM, a citation analysis study was conducted. Because of the analysis carried out, the names of the publications that are classified according to the types of publications reached and the type of publications are listed. According to the results, the first 176 journals in the field of TM meet the $70 \%$ of the need for the area. In other words, first 176 Journals Citation Rate $\% 70$. Bradford's Law of Scattering defines the scattering or distribution of literature on a particular subject $[27,28]$. According to the Bradford Law, first formulated in 1934, if scientific journals are organized in order of decreasing efficiency in articles published in a specific subject, journals can be divided into a core group of magazines that publish only articles on this subject and many groups or regions containing the same number of articles as the core group [28].

In other words, Bradford Law is used to determine which of the journals on a specific topic are the core journals. 


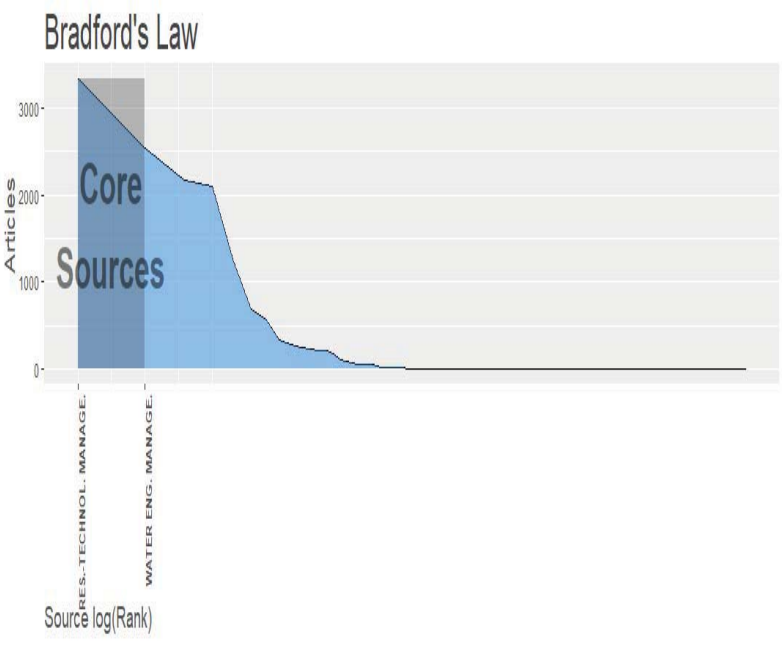

Fig. 3. Core Journals for TM

According to this law, journals are divided into three groups with the same number of articles; the number of journals in the first group is small but includes 1 in 3 of the total articles. These are core journals. The number of journals in the second group is higher and the articles they publish are $1 / 3$ of all articles. The number of journals in the last group is much more, but the same includes $1 / 3$ of the article. According to this information, the most commonly used intellectual content in the TM area is presented in table 1.

According to Bradford's law of Distribution, it is seen that there are two journals ("Research-Technology Management" and "Water Engineering and Management") in the first region in the distribution of journals for TM. The second regions journals are "IEEE Transactions on Engineering Management",

"International Journal of Technology Management (IJTM)" and "Gas Engineering and Management". In the 3rd region there are 987 individual journals with articles published in TM area.
TABLE I.

CORE JOURNAL LIST FOR TM

\begin{tabular}{|l|c|c|c|c|}
\hline SO & Rank & Freq & cumFreq & Zone \\
\hline RES.-TECHNOL. MANAGE. & 1 & 3332 & 3332 & Zone 1 \\
\hline WATER ENG. MANAGE. & 2 & 2542 & 5874 & Zone 1 \\
\hline IEEE TRANS. ENG. MANAGE. & 3 & 2171 & 8045 & Zone 2 \\
\hline INT. J. TECHNOL. MANAGE. & 4 & 2091 & 10136 & Zone 2 \\
\hline GAS ENG. MANAGE. & 5 & 1240 & 11376 & Zone 2 \\
\hline ADV. SCI. LETT. & 6 & 689 & 12065 & Zone 3 \\
\hline J. ENG. TECHNOL. MANAGE. & 7 & 562 & 12627 & Zone 3 \\
\hline EMJ-ENG. MANAG. J. & 8 & 349 & 12976 & Zone 3 \\
\hline INF. TECHNOL. MANAG. & 9 & 297 & 13273 & Zone 3 \\
\hline FRONT. ENG. MANAG. & 10 & 247 & 13520 & Zone 3 \\
\hline INT. J. INNOV. TECHNOL. MANAG. & 11 & 233 & 13753 & Zone 3 \\
\hline J. MANUF. TECHNOL. MANAG. & 12 & 218 & 13971 & Zone 3 \\
\hline J. GLOB. INF. TECHNOL. MANAG. & 13 & 212 & 14183 & Zone 3 \\
\hline ADV. PROD. ENG. MANAG. & 14 & 177 & 14360 & Zone 3 \\
\hline INT. J. MANAG. SCI. ENG. MANAG. & 16 & 114 & 14474 & Zone 3 \\
\hline INT. TRANS. J. ENG. MANAG. APPL. SCI. TECHNOL. & 16 & 14566 & Zone 3 \\
\hline TECHNOL. FORECAST. SOC. CHANG. & 70 & 14636 & Zone 3 \\
\hline TECHNOVATION & 14704 & Zone 3 \\
\hline
\end{tabular}

\section{PICMET Proceeding Papers and Their Contribtiuns to the TEM area}

2754 PICMET papers were examined in terms of their contribution to the TEM literature. The topics discussed in the PICMET conferences, which have been held regularly since 2009, and the sub-headings in which they are aggregated are visualized. According to this the topics discussed in the PICMET conferences, which have been held regularly since 2009, and the sub-topics in which they are aggregated are visualized. Accordingly, it is possible to talk about the groups



Fig. 4 PICMET Topics \& Cluster 
of "CO2 emision", "optimal cognitive distance", "large scale ict innovation", "relational demography" and "game software companies". When the visual is examined closely, it is possible to observe that all clusters except the game software companies are discussed in conferences almost every year, especially the health topic under the "relational demographics" trend (Fig 4).

\section{University Impact}

Portland State University is at the top of the list according to the results of the analysis conducted to determine the most effective universities in PICMET. From this perspective While Asian universities have more frequent relationships with each other, there is a strong relationship between American universities. The effect of Portland State University is clearly seen when the author collaborations and citation numbers are taken together. In terms of collaboration, it is seen that Asian Universities form a cluster within themselves, and is another cluster at the center of Portland State University. Although it is observed that there are clusters formed by institutions such as Brazil, Japan, China and Korea, it is clear that these clusters are not related to other clusters. In this respect, it can be said that the institutions contributing to the PICMET papers are working within themselves (Fig 6).

\section{DISCUSSION}

It was possible to access the list of core journals for the TM area with the analyzes performed. The journals which are the most frequently published articles in the TM area are identified with the core journal list. In order to determine the intellectual content used in the production of the articles published in the field of TM, the citation analysis study was conducted and the information of the most frequently cited journals was obtained. In this way, tools have to be developed to be able to follow the TM literature effectively. The Bradford Law and citation analysis principles were used in the creation of these instruments. It should be noted that the data set discussed in the analysis is obtained from $\mathrm{WoS}$ and that the publication data accessed is directly influenced by the indexing method of the relevant database. In this study, it is possible to say that the core journals related to TM field is determined in our research. On the other hand, it was observed that the studies published in the field of TM were not only limited to the periodicals, during the analyzes, but also as proceedings, books and book chapters. PICMET as a core source also provides significant content to the field. The most productive Authors, institutions and countries are identified in the field of TEM. With more indepth analyzes, it will be possible to identify the research groups with expertise and competence in the sub-subject areas of TEM and to identify possible cooperation models among these groups. In this respect, it is possible to say that a tool has been reached, which can be used primarily by both field researchers and those who will start new research in the field. It is worth mentioning that two basic problems have been answered.

1: What are the most frequently published journals in the TM area?

2: What are the most frequently cited journals in the publications published in the TM area?



Fig. 5 University Productivity (PICMET Documents All Years) 


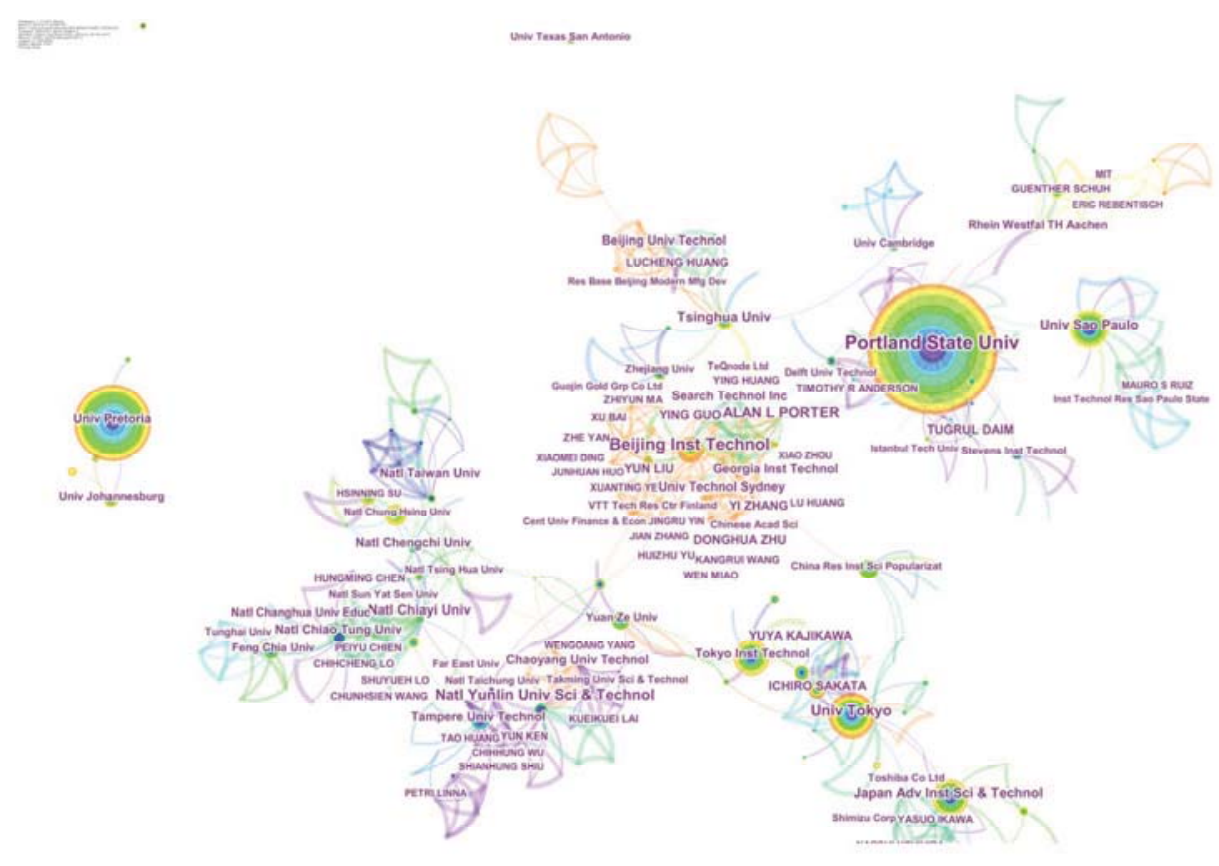

Fig. 6 Universities Collaboration Clusters Over Years

\section{ACKNOWLEDGMENTS}

This work was supported by Scientific and Technological Research Council of Turkey Postdoctoral Research Programme (TUBITAK BIDEP 2219) [1059B191700840].

\section{REFERENCES}

[1] T. U. Daim, G. Rueda, H. Martin, and P. Gerdsri, "Forecasting emerging technologies: Use of bibliometrics and patent analysis," (in English), Technological Forecasting and Social Change, vol. 73, no. 8, pp. 9811012 , Oct 2006

[2] T. R. Anderson, T. U. Daim, and J. Kim, "Technology forecasting for wireless communication," (in English), Technovation, vol. 28, no. 9, pp. 602-614, Sep 2008.

[3] D. F. Kocaoglu, T. U. Daim, and A. J. Jetter, "Defining the Research Agenda: Technology Management as a Contributor to Service Sciences, Management and Engineering," (in English), Service Science, Management and Engineering Education for the 21st Century, pp. 5560, 2008.

[4] M. Broddle, "We are all managers now," Computing and Control Engineering Journal, Article vol. 2, no. 4, pp. 151-155, 1991.

[5] R. Whipp, "Managing technological changes. Opportunities and pitfalls," International Journal of Vehicle Design, Article vol. 12, no. 56, pp. 469-477, 1991

[6] W. Baets, "Aligning information systems with business strategy," Journal of Strategic Information Systems, Article vol. 1, no. 4, pp. 205 213, 1992.

[7] M. L. Dickerson and M. E. Jackson, "Technology management: A perspective on system support, procurement, and replacement planning," Journal of Clinical Engineering, Article vol. 17, no. 2, pp. 129-136, 1992.

[8] C. Kirk and R. Chapman, "Science and technology management: Designing an undergraduate course," Research in Science Education, Article vol. 22, no. 1, pp. 255-259, 1992.

[9] C. H. Nam and C. B. Tatum, "Strategies for technology push: Lessons from construction innovations," Journal of Construction Engineering and Management, Article vol. 118, no. 3, pp. 507-524, 1992.

[10] J. Ranta, M. Ollus, and A. Leppänen, "Information technology and structural change in the paper and pulp industry. Some technological, organizational and managerial implications," Computers in Industry, Article vol. 20, no. 3, pp. 255-269, 1992.

[11] W. E. Spangler and J. H. May, "Success and failure in cooperative expert systems development: A tale of two projects," The Journal of Systems and Software, Article vol. 19, no. 2, pp. 131-140, 1992.

[12] M. M. Zolfagharzadeh, A. Aslani, A. A. Sadabadi, M. Sanaei, F. Lesan Toosi, and M. Hajari, "Science and technology diplomacy: a framework at the national level," Journal of Science and Technology Policy Management, Article vol. 8, no. 2, pp. 98-128, 2017.

[13] Y. Chandra, "Mapping the evolution of entrepreneurship as a field of research (1990-2013): A scientometric analysis," PLOS ONE, Article vol. 13, no. 1, 2018, Art. no. e0190228.

[14] T. U. Daim, B. S. Yoon, J. Lindenberg, R. Grizzi, J. Estep, and T. Oliver, "Strategic roadmapping of robotics technologies for the power industry: A multicriteria technology assessment," Technological Forecasting and Social Change, Article vol. 131, pp. 49-66, 2018.

[15] R. Hafezi, S. Malekifar, and A. Akhavan, "Analyzing Iran's science and technology foresight programs: recommendations for further practices," Foresight, Article vol. 20, no. 3, pp. 312-331, 2018.

[16] S. Jun, J. Wood, and S. Park, "Multivariate multiple regression modelling for technology analysis," Technology Analysis and Strategic Management, Article vol. 30, no. 3, pp. 311-323, 2018

[17] J. Kim, J. Choi, S. Park, and D. Jang, "Patent keyword extraction for sustainable technology management," Sustainability (Switzerland), Article vol. 10, no. 4, 2018, Art. no. 1287.

[18] F. Meyer-Brötz, B. Stelzer, E. Schiebel, and L. Brecht, "Mapping the technology and innovation management literature using hybrid bibliometric networks," International Journal of Technology Management, Article vol. 77, no. 4, pp. 235-286, 2018.

[19] A. Saurikhia, S. Ahmed, A. Haleem, S. Gangopadhyay, and M. I. Khan, "Evaluating technology management factors for fly-ash utilization in the road sector using an ISM approach," International Journal of Management Science and Engineering Management, Article vol. 13, no. 2, pp. 108-117, 2018.

[20] B. Yoon, J. Shin, and S. Lee, "Technology assessment model for sustainable development of LNG terminals," Journal of Cleaner Production, Article vol. 172, pp. 927-937, 2018.

[21] T. U. Daim, K. van Blommestein, N. Islam, S. Ozcan, J. Hillegas, and J. Estep, "Integrating Data Mining into Technology Roadmapping," (in English), 2014 Portland International Conference on Management of Engineering \& Technology (Picmet), pp. 2972-2985, 2014.

[22] U. Al, I. Soydal, and H. Yalcin, "An Evaluation of the Bibliometric Features of bilig," Bilig, no. 55, pp. 1-20, Fal 2010. 
[23] H. Yalcin, "Bibliometric Profile of Journal of National Folklore (20072009)," Milli Folklor, no. 85, pp. 205-211, Spr 2010

[24] H. Yalcin and K. Yayla, "A Strategy Proposal for the Journals Published in the Social and Human Sciences," Tarih Incelemeleri Dergisi, vol. 31, no. 2, pp. 609-638, 2016.

[25] H. Yalcin and K. Yayla, "Main Dynamics of Folklore Discipline: a Scientometric Analysis," Milli Folklor, no. 112, pp. 42-60, Win 2016.
[26] H. Yalcin and K. Yayla, "Scientometric Analysis of the Researches About Technological Pedagogical Content Knowledge and Scholarly Communication," Egitim Ve Bilim-Education and Science, vol. 41, no. 188, pp. 291-307, Nov 2016.

[27] E. Garfield, "Bradford Law and Related Statistical Patterns," Current Contents, no. 19, pp. 5-12, 1980.

[28] Y. Tonta and U. Al, "Türkçe makalelerin dergilere dağılımı ve Bradford Yasas1," Bilgi Dünyast, vol. 9, no. 1, pp. 41-66, 2008. 